\title{
Undifferentiated Round Cell Sarcoma
}

National Cancer Institute

\section{Source}

National Cancer Institute. Undifferentiated Round Cell Sarcoma. NCI Thesaurus. Code C121799.

An undifferentiated soft tissue sarcoma characterized by the presence of uniform round or ovoid malignant cells with a high nuclear to cytoplasmic ratio. 